\title{
The effect of ZnO surface conditions on the electronic structure of the $\mathrm{ZnO} / \mathrm{CuPc}$ interface
}

\author{
Sang Han Park, ${ }^{1}$ Hyo Jin Kim, ${ }^{1}$ Mann-Ho Cho, ${ }^{1, a)}$ Yeonjin Yi, ${ }^{2}$ Sang Wan Cho, ${ }^{3}$ \\ Jaehyun Yang, ${ }^{4}$ and Hyoungsub $\mathrm{Kim}^{4}$ \\ ${ }_{1}^{1}$ Institute of Physics and Applied Physics, Yonsei University, Seoul 120-749, Republic of Korea \\ ${ }^{2}$ Division of Industrial Metrology, KRISS, Daejeon 305-340, Republic of Korea \\ ${ }^{3}$ Department of Physics, Boston University, 590 Commonwealth Avenue, Boston, Massachusetts 02215, USA \\ ${ }^{4}$ School of Advanced Materials Science and Engineering, Sungkyunkwan University, Suwon 440-746, \\ Republic of Korea
}

(Received 14 December 2010; accepted 25 January 2011; published online 23 February 2011)

\begin{abstract}
The interfacial electronic structures of zinc oxide $(\mathrm{ZnO}) /$ copper-phthalocyanine $(\mathrm{CuPc})$ were investigated by in situ x-ray and ultraviolet photoelectron spectroscopy (UPS) to determine the effects of air contamination on the $\mathrm{ZnO}$ substrate. UPS spectra showed that the $0.2 \mathrm{eV}$ of the interface dipole is generated at the interface of the air exposed $\mathrm{ZnO} / \mathrm{CuPc}$ while the interface of the annealed $\mathrm{ZnO} / \mathrm{CuPc}$ generated $-0.2 \mathrm{eV}$. In both cases, no band bending was observed. On the other hand, band bending at $0.3 \mathrm{eV}$ and an interface dipole of $0.2 \mathrm{eV}$ were observed at the interface of the sputter cleaned $\mathrm{ZnO} / \mathrm{CuPc}$. The energy offset between the conduction band maximum of $\mathrm{ZnO}$ and the highest occupied molecular orbital of $\mathrm{CuPc}$ was determined to be $0.6-0.7 \mathrm{eV}$ for the contaminated $\mathrm{ZnO}$ interface while the offset was $1.0 \mathrm{eV}$ for the cleaned $\mathrm{ZnO}$ interface. Contaminating moisture has little effect on the offset while the charge transfer was blocked and the offset was decreased in the presence of hydrocarbons. () 2011 American Institute of Physics. [doi:10.1063/1.3555440]
\end{abstract}

In recent years, organic photovoltaic (OPV) devices have attracted considerable attention due to their low cost, ease of fabrication, and their flexibility. ${ }^{1}$ Many research groups have reported on attempts to improve their performances in terms of efficiency and stability. In particular, to overcome the weakness of organic materials, which include short exciton diffusion length and air instability, organicinorganic hybrid structures are generally considered to be promising applications. ${ }^{2}$ In this respect, zinc oxide $(\mathrm{ZnO})$ is the most widely used inorganic semiconductor in this type of hybrid device because of its high transparency, nontoxicity, the ease of fabrication of thin films and nanostructure properties. In addition, $\mathrm{ZnO}$ /organic hybrid photovoltaic devices with inverted structures show a more stable performance in air than other organic-only devices. ${ }^{3}$

However, this hybrid device is usually contaminated at the organic/inorganic interface, as the result of the ex situ process associated with the different deposition methods between $\mathrm{ZnO}$ and the organic material. The presence of this contaminant may lead to interfacial states and the development of a tunneling barrier. ${ }^{4}$ Although some concerns exist regarding this type of hybrid device due to the ex situ process used, a detailed understanding of the interfacial electronic structure with organic molecules in hybrid applications of $\mathrm{ZnO}$ is not available while the electronic structure and chemical bonding of organic molecules with single crystalline $\mathrm{ZnO}$ particles has been investigated. ${ }^{5}$ A number of studies regarding the preparation of OPVs using copperphthalocyanine $(\mathrm{CuPc})$ haves been reported because of the appropriate band gap and desirable absorption properties of $\mathrm{CuPc}$.

\footnotetext{
a) Author to whom correspondence should be addressed. Electronic mail: mh.cho@yonsei.ac.kr.
}

In this letter, we report on a study of the electronic structure and energy level alignments of the $\mathrm{ZnO} / \mathrm{CuPc}$ interface using X-ray and ultraviolet photoemission spectroscopy (XPS and UPS) during the stepwise deposition of $\mathrm{CuPc}$ on each $\mathrm{ZnO}$ films. The samples were then exposed to air, postannealed after air exposure, and cleaned by $\mathrm{Ar}^{+}$sputtering. This permitted us to investigate the blocking of charge transfer at the $\mathrm{ZnO} / \mathrm{CuPc}$ interface, as the result of carbon contamination.

$100 \mathrm{~nm}$ thick $\mathrm{ZnO}$ films were deposited on indium tin oxide (ITO) coated glass substrates using a radio frequency sputtering method with a power of $150 \mathrm{~W}$. The $\mathrm{ZnO}$ film showed a (0001) preferred orientation and the properties of the films characterized, as described in a previous paper. ${ }^{6} \mathrm{We}$ prepared various types of $\mathrm{ZnO}$ films and the surface was exposed to a laboratory ambient, annealed in an analysis chamber for $30 \mathrm{~min}$ at $300{ }^{\circ} \mathrm{C}$, and cleaned by sputtering using $\mathrm{Ar}^{+}$ions for $3 \mathrm{~min}$. In the in situ measurements, the $\mathrm{CuPc}$ (Sigma-Aldrich Co.) was thermally deposited in a deposition chamber that was directly connected to the analysis chamber. We collected photoemission spectra after each deposition step of $\mathrm{CuPc}$, where the $\mathrm{CuPc}$ was deposited in steps of $0.2,0.5,1.0,2.0,5.0,10.0$, and $20.0 \mathrm{~nm}$ on each $\mathrm{ZnO}$ substrate. The analysis chamber was equipped with a hemispherical electron energy analyzer (PHI 5700 spectrometer), a monochromatic $\mathrm{x}$-ray source ( $\mathrm{Al} K \alpha, 1486.6 \mathrm{eV})$ and an unfiltered UV (He I, $21.2 \mathrm{eV}$ ) source. A sample bias of $-15 \mathrm{~V}$ was applied to measure the work function of the sample. The energy scale of the spectra shown was calibrated with the Fermi level of the sputter cleaned Au substrate.

Figure 1 shows (a) the valance band region of UPS spectra, (b) the position for secondary electron (SE) cutoff shift for the interface between $\mathrm{CuPc}$ and air exposed $\mathrm{ZnO}$, and (c) XPS spectra of oxygen and carbon at the air exposed $\mathrm{ZnO}$ 




FIG. 1. (Color online) (a) Valance band region of UPS spectra and (b) SE cutoff position shift in CuPc deposited on air exposed $\mathrm{ZnO}$ film. (c) The $\mathrm{O} 1 s$ and C $1 s$ XPS spectra for air contaminated $\mathrm{ZnO}$ surface.

surface. All spectra were normalized to permit the effect of interface state to be clearly compared. The top spectrum in Fig. 1(a) shows that the characteristic emission features of $\mathrm{CuPc}$ in the valence region emerge in the $\mathrm{CuPc}$ sample that was grown on an air exposed $\mathrm{ZnO}$ film. The highest occupied molecular orbital (HOMO) onset of the CuPc is $1.2 \mathrm{eV}$ from the Fermi level and a peak shift was not observed in either the XPS or UPS spectra during the deposition sequence, as indicated by the vertical line in the spectrum. This result implies the absence of band bending at the interface. The SE cutoff position shifts toward low binding energies and the shifts become saturated when the $\mathrm{CuPc}$ reaches a thickness of $2 \mathrm{~nm}$, as shown in Fig. 1(b). This total shift of $0.2 \mathrm{eV}$ can be attributed to the interface dipole $(\mathrm{eD})$ because band bending does not occur. The XPS spectra in Fig. 1(c)

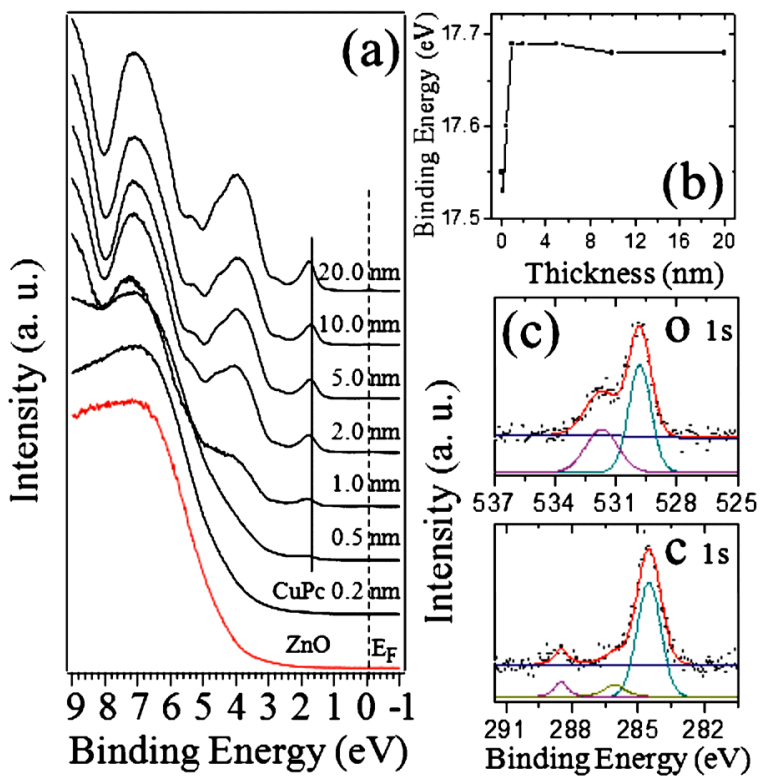

FIG. 2. (Color online) (a) Valance band region of UPS spectra and (b) SE cutoff position shift in $\mathrm{CuPc}$ deposited on a postannealed $\mathrm{ZnO}$ film. (c) $\mathrm{O} 1 s$ and $\mathrm{C} 1 s$ XPS spectra for a postannealed $\mathrm{ZnO}$ surface.

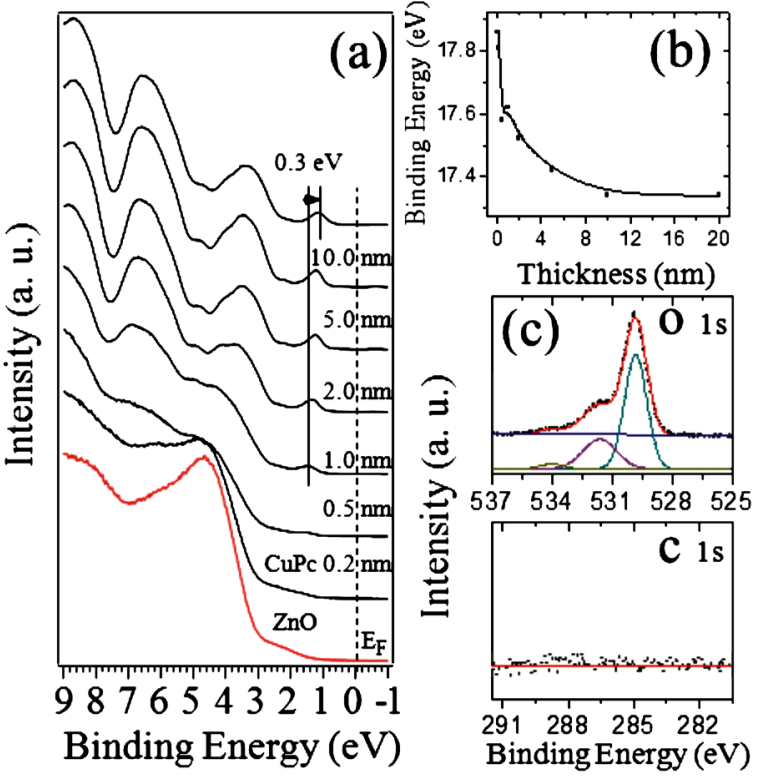

FIG. 3. (Color online) (a) Valance band region of UPS spectra and (b) SE cutoff position shift in $\mathrm{CuPc}$ deposited on a sputter cleaned $\mathrm{ZnO}$ film. (c) $\mathrm{O} 1 s$ and C $1 s$ XPS spectra for sputter cleaned $\mathrm{ZnO}$ surface. $0.2 \mathrm{eV}$ of interface dipole with $0.3 \mathrm{eV}$ of bend banding was observed with a clean surface.

show that a quantity of water and hydrocarbon were absorbed on the air exposed $\mathrm{ZnO}$ surface. The $\mathrm{O} 1 \mathrm{~s}$ peaks at 529.8 and $531.6 \mathrm{eV}$ are assigned to oxygen atoms in a fully oxidized stoichiometric surrounding and to hydroxyl groups or intermediate states between $\mathrm{O}^{2-}$ and dissociated oxygen $\left(\mathrm{O}^{1-}\right)$, respectively. ${ }^{7}$

In order to eliminate the effect of adsorbed water on the surface, the air exposed $\mathrm{ZnO}$ film was annealed at a relatively low temperature of $300{ }^{\circ} \mathrm{C}$ for $30 \mathrm{~min}$ in a analysis chamber, because the structural transformation of $\mathrm{ZnO}$ occurs at higher temperature of $450{ }^{\circ} \mathrm{C}^{8}$. The chemical state of the annealed $\mathrm{ZnO}$ surface was examined using XPS. A comparison of XPS O $1 s$ spectra of an air exposed $\mathrm{ZnO}$ film with that of an annealed film, confirmed that adsorbed water was removed, as evidenced by the fact that the peak at 531.6 $\mathrm{eV}$ was drastically decreased at the annealing temperature of $300{ }^{\circ} \mathrm{C}$. On the other hand, the same intensity of the C 1 s spectra in the air-exposed film before and after the annealing treatment indicates that hydrocarbons are not desorbed from air exposed $\mathrm{ZnO}$ surface. After the annealing treatment of $\mathrm{ZnO}$, we investigated the energy state in detail using UPS, as shown in Fig. 2(a). The HOMO onset of $\mathrm{CuPc}$ was constant at $1.4 \mathrm{eV}$ during the deposition and the electron affinity $(\chi)$ of $\mathrm{ZnO}$ was measured at $4.3 \mathrm{eV}$. Moreover, the SE cutoff position shift in (b) was $0.2 \mathrm{eV}$ toward higher binding energy, which is opposite that for the dipole of the air exposed $\mathrm{ZnO} / \mathrm{CuPc}$ interface. Therefore, a $-0.2 \mathrm{eV}$ interface dipole without band bending is formed at just the hydrocarbon terminated surface.

After $\mathrm{Ar}^{+}$sputtering for $3 \mathrm{~min}$, we investigated the $\mathrm{ZnO}$ surface using XPS, as shown in Fig. 3(c). The C $1 s$ peak was not observed on the $\mathrm{ZnO}$ surface cleaned by $\mathrm{Ar}^{+}$sputtering. On the other hand, the O $1 s$ peak in the XPS spectrum after the cleaning process was not significantly different from that of the annealed film, as shown in Fig. 2(c). The change in UPS spectrum of the cleaned $\mathrm{ZnO}$ surface provides more important information, as shown in the $\mathrm{O} 2 p$ 


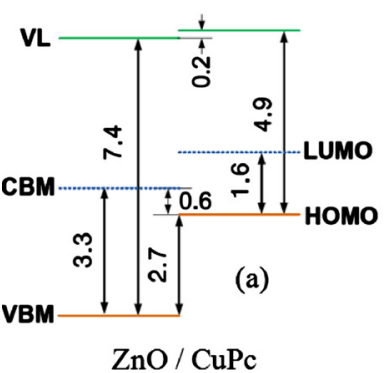

$\mathrm{ZnO} / \mathrm{CuPc}$

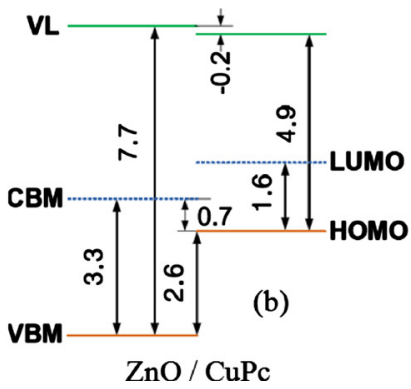

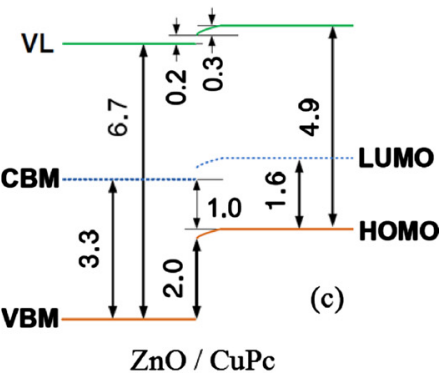

FIG. 4. (Color online) Energy level diagram of $\mathrm{ZnO} / \mathrm{CuPc}$ for (a) air contaminated $\mathrm{ZnO}$, (b) postannealed $\mathrm{ZnO}$, and (c) sputter cleaned $\mathrm{ZnO}$. The energy offset between CVM of $\mathrm{ZnO}$ and LUMO of $\mathrm{CuPc}$ which affect Voc are (a) $0.6 \mathrm{eV}$, (b) $0.7 \mathrm{eV}$, and (c) $1.0 \mathrm{eV}$. state of Fig. 3(a). The $\chi$ of sputter cleaned $\mathrm{ZnO}(3.4 \mathrm{eV})$ is in good agreement with previous results for a $\mathrm{Zn}$ terminated $\mathrm{ZnO}$ surface (0001) because oxygen on the surface is preferentially removed by sputtering during the cleaning process. ${ }^{9}$ The valence band maximum (VBM) of $\mathrm{ZnO}$ and the HOMO onset position appear at $3.0 \mathrm{eV}$ and $0.7 \mathrm{eV}$ from the Fermi level, respectively. During the subsequent deposition of $\mathrm{CuPc}$ on the sputtered $\mathrm{ZnO}$ surface, the HOMO onset position is shifted to lower binding energy by $0.3 \mathrm{eV}$. Moreover, only a rigid spectral shift by $0.3 \mathrm{eV}$ in $\mathrm{Cu} 2 p, \mathrm{~N} 1 s$, and $\mathrm{C} 1 \mathrm{~s}$ is observed. The consistent shift values indicate that band bending of about $0.3 \mathrm{eV}$, is generated. Since the total SE cutoff position shift caused by contributions by both the eD and band bending toward a lower binding energy up to $0.5 \mathrm{eV}$, as shown in Fig. 3(b), the eD between sputtered $\mathrm{ZnO}$ and $\mathrm{CuPc}, 0.2 \mathrm{eV}$, can be calculated.

Combining all of spectral changes, we drew the band alignments between $\mathrm{ZnO}$ and $\mathrm{CuPc}$, as shown in Fig. 4. The vacuum level of the $\mathrm{ZnO}$ film was obtained with a position of the SE cutoff and the VBM. We estimated the conduction band minimum (CBM) and the lowest unoccupied molecular orbital (LUMO) position from the reported energy gap of $\mathrm{ZnO}(3.3 \mathrm{eV})$ and $\mathrm{CuPc}(1.6 \mathrm{eV})$, respectively. ${ }^{10,11}$ The $\chi$ for $\mathrm{ZnO}$ and an ionization energy of $\mathrm{CuPc}$ were determined to be 4.0 and $4.9 \mathrm{eV}$, which are consistent with previously reported values within the error margin of our measurements. ${ }^{9,12}$ The band alignment between air exposed $\mathrm{ZnO}$ and $\mathrm{CuPc}$ in Fig. 4(a) is indicative of a typical staggered junction with a positive $0.2 \mathrm{eV}$ for $\mathrm{eD}$ due to charge redistribution. (We defined the positive sign of $\mathrm{eD}$ as the direction of the electric field from $\mathrm{ZnO}$ to $\mathrm{CuPc}$ ) The eD, in this case, is not accompanied by a charge transfer from p-type $\mathrm{CuPc}$ to n-type $\mathrm{ZnO}$ because band bending does not occur. Therefore, charge transfer across $\mathrm{ZnO}$ /organic interface can be achieved while that from $\mathrm{CuPc}$ to $\mathrm{ZnO}$ can be blocked by the presence of water or hydrocarbons that are absorbed during the air exposure of the $\mathrm{ZnO}$ surface. ${ }^{13}$ Another important finding is that the energy offset between the CBM for $\mathrm{ZnO}$ and the HOMO for $\mathrm{CuPc}$ was determined to be $0.6 \mathrm{eV}$, which is believed to be proportional to the open circuit voltage of an organic solar cell. ${ }^{14}$ After the annealing treatment, the charge transfer between $\mathrm{ZnO}$ and $\mathrm{CuPc}$ also is not sufficient to bend the electronic structure. The related band diagram is shown in Fig. 4(b). The energy offset between the CBM for $\mathrm{ZnO}$ and the HOMO for $\mathrm{CuPc}$ was $0.7 \mathrm{eV}$ and this value was not affected by the annealing treatment, in spite of the opposite direction of eD. Band bending of CuPc was observed only at the cleaned $\mathrm{ZnO}$ surface as shown in Fig. 4(c). This band bending occurred due to the depletion region of the $\mathrm{CuPc}$ layer by charge transfer across the $\mathrm{ZnO} / \mathrm{CuPc}$ interface. As a result of
$\mathrm{eD}$ and band bending, a larger energy offset $(1.0 \mathrm{eV})$ between $\mathrm{CBM}$ of $\mathrm{ZnO}$ and $\mathrm{HOMO}$ of $\mathrm{CuPc}$ was formed in the case of the cleaned $\mathrm{ZnO}$, compared to the contaminated $\mathrm{ZnO}$.

The results reported herein, indicate that $\mathrm{ZnO} / \mathrm{CuPc}$ hybrid structures have some promise for use in photovoltaic applications. The electronic structure of the clean $\mathrm{ZnO} / \mathrm{CuPc}$ interface shows band bending of the typical p-n junction and electron transfer from $\mathrm{CuPc}$ as a donor to $\mathrm{ZnO}$ as an accepter in photovoltaic applications. In addition, the band offset between $\mathrm{CBM}$ of $\mathrm{ZnO}$ and $\mathrm{HOMO}$ of $\mathrm{CuPc}$ is sufficiently large to allow for efficient charge separation $(1.0 \mathrm{eV})$. However, contamination of the $\mathrm{ZnO}$ surface by hydrocarbons can have a critical effect on band structure. The band offset was reduced from 1.0 to $0.7 \mathrm{eV}$ and the charge transfer was significantly decreased in cases of such contamination. For the case of moisture, contaminating water lowed the $\chi$ of $\mathrm{ZnO}$ and $\mathrm{eD}$ at the interface while the band offset changed just $0.1 \mathrm{eV}$ and the interfacial electronic structure was barely effected.

This work was supported by the IT R\&D program of MKE/KEIT (Grant No. 10032091, Development of the large-scale solar cell Equipment Technology) and New and Renewable Energy R\&D Program (Grant No. 2009T100100614) under the Ministry of Knowledge Economy, Republic of Korea.

${ }^{1}$ J.-M. Nunzi, C. R. Phys. 3, 523 (2002).

${ }^{2}$ D. Cui, J. Xu, T. Zhu, G. Paradee, S. Ashok, and M. Gerhold, Appl. Phys. Lett. 88, 183111 (2006).

${ }^{3}$ J. P. Liu, S. S. Wang, Z. Q. Bian, M. N. Shan, and C. H. Huang, Chem. Phys. Lett. 470, 103 (2009).

${ }^{4}$ B. J. Coppa, C. C. Fulton, S. M. Kiesel, R. F. Davis, C. Pandarinath, J. E. Burnette, R. J. Nemanich, and D. J. Smith, J. Appl. Phys. 97, 103517 (2005).

${ }^{5}$ G. W. Rubloff, H. Luth, and W. D. Grobman, Chem. Phys. Lett. 39, 493 (1976).

${ }^{6}$ B.-I. Hwang, K. Park, H.-S. Chun, C.-H. An, H. Kim, and H.-J. Lee, Appl. Phys. Lett. 93, 222104 (2008).

${ }^{7}$ C. Yang, C. Lin, C. Peng, and S. Chen, J. Cryst. Growth 285, 96 (2005).

${ }^{8}$ H. H. P. T. Bekman, K. W. Benoist, and J. L. Joppe, Appl. Surf. Sci. 70-71, 347 (1993).

${ }^{9}$ K. Jacobi, G. Zwicker, and A. Gutmann, Surf. Sci. 141, 109 (1984).

${ }^{10}$ V. Srikant and D. R. Clarke, J. Appl. Phys. 83, 5447 (1998).

${ }^{11}$ I. G. Hill, D. Milliron, J. Schwartz, and A. Kahn, Appl. Surf. Sci. 166, 354 (2000).

${ }^{12}$ S. T. Lee, Y. M. Wang, X. Y. Hou, and C. W. Tang, Appl. Phys. Lett. 74, 670 (1999).

${ }^{13}$ S. Blumstengel, N. Koch, S. Sadofev, P. Schafer, H. Glowatzki, R. L. Johnson, J. P. Rabe, and F. Henneberger, Appl. Phys. Lett. 92, 193303 (2008).

${ }^{14}$ C. J. Brabec, A. Cravino, D. Meissner, N. Serdar Sariciftci, T. Fromherz, M. T. Rispens, L. Sanchez, and J. C. Hummelen, Adv. Funct. Mater. 11, 374 (2001). 